University of South Florida

DIGITAL COMMONS

Digital Commons @ University of

@ UNIVERSITY OF SOUTH FLORIDA

South Florida

\title{
The Ocean Carbon Response to COVID-Related Emissions Reductions
}

\author{
Nicole S. Lovenduski \\ University of Colorado \\ Neil C. Swart \\ Environment and Climate Change Canada \\ Adrienne J. Sutton \\ National Oceanic and Atmospheric Administration, Seattle \\ John C. Fyfe \\ Environment and Climate Change Canada \\ Galen A. McKinley \\ Columbia University
}

See next page for additional authors

Follow this and additional works at: https://digitalcommons.usf.edu/usf_fcrc_all

\section{Scholar Commons Citation \\ Lovenduski, Nicole S.; Swart, Neil C.; Sutton, Adrienne J.; Fyfe, John C.; McKinley, Galen A.; Sabine, Christopher; and Williams, Nancy L., "The Ocean Carbon Response to COVID-Related Emissions Reductions" (2021). All publications. 89. \\ https://digitalcommons.usf.edu/usf_fcrc_all/89}

This Article is brought to you for free and open access by the USF Libraries Florida COVID-19 Research Collections at Digital Commons @ University of South Florida. It has been accepted for inclusion in All publications by an authorized administrator of Digital Commons @ University of South Florida. For more information, please contact digitalcommons@usf.edu. 


\section{Authors}

Nicole S. Lovenduski, Neil C. Swart, Adrienne J. Sutton, John C. Fyfe, Galen A. McKinley, Christopher Sabine, and Nancy L. Williams 


\section{Geophysical Research Letters}

\author{
RESEARCH LETTER \\ 10.1029/2020GL092263 \\ Key Points: \\ - COVID-related emissions reductions \\ will be imperceptible in surface \\ ocean $\mathrm{pH}$ observations \\ - The CanESM5 COVID ensemble \\ predicts a unique fingerprint of \\ COVID-related emissions reductions \\ in global mean $\Delta \mathrm{pCO}_{2}\left(\mathrm{pCO}_{2}^{o c}-\mathrm{p}\right.$ \\ $\mathrm{CO}_{2}^{a t m}$ ) \\ - The fingerprint is potentially \\ detectable in global-scale \\ observations of $\Delta \mathrm{pCO}_{2}$, but only \\ with large emissions reductions
}

Correspondence to:

N. S. Lovenduski,

nicole.lovenduski@colorado.edu

Citation:

Lovenduski, N. S., Swart, N. C., Sutton, A. J., Fyfe, J. C., McKinley, G. A., Sabine, C., \& Williams, N. L. (2021). The ocean carbon response to COVID-related emissions reductions. Geophysical Research Letters, 48, e2020GL092263. https://doi. org/10.1029/2020GL092263

Received 23 DEC 2020 Accepted 24 FEB 2021

(C) 2021. American Geophysical Union. All Rights Reserved.

\section{The Ocean Carbon Response to COVID-Related Emissions Reductions}

\author{
Nicole S. Lovenduski ${ }^{1}$ (D), Neil C. Swart ${ }^{2}$ iD, Adrienne J. Sutton ${ }^{3}$ (D) John C. Fyfe ${ }^{2}$, \\ Galen A. McKinley ${ }^{4}$ (D), Christopher Sabine ${ }^{5}$ (D), and Nancy L. Williams ${ }^{6}$ (D)
}

${ }^{1}$ Department of Atmospheric and Oceanic Sciences and Institute of Arctic and Alpine Research, University of Colorado, Boulder, CO, USA, ${ }^{2}$ Canadian Centre for Climate Modelling and Analysis, Environment and Climate Change Canada, Victoria, BC, Canada, ${ }^{3}$ Pacific Marine Environmental Laboratory, National Oceanic and Atmospheric Administration, Seattle, WA, USA, ${ }^{4}$ Columbia University and Lamont Doherty Earth Observatory, Palisades, NY, USA, ${ }^{5}$ Department of Oceanography, University of Hawai'i at Manoa, Honolulu, HI, USA, ${ }^{6}$ College of Marine Science, University of South Florida, St. Petersburg, FL, USA

Abstract The decline in global emissions of carbon dioxide due to the COVID-19 pandemic provides a unique opportunity to investigate the sensitivity of the global carbon cycle and climate system to emissions reductions. Recent efforts to study the response to these emissions declines has not addressed their impact on the ocean, yet ocean carbon absorption is particularly susceptible to changing atmospheric carbon concentrations. Here, we use ensembles of simulations conducted with an Earth system model to explore the potential detection of COVID-related emissions reductions in the partial pressure difference in carbon dioxide between the surface ocean and overlying atmosphere $\left(\Delta \mathrm{pCO}_{2}\right)$, a quantity that is regularly measured. We find a unique fingerprint in global-scale $\Delta \mathrm{pCO}_{2}$ that is attributable to COVID, though the fingerprint is difficult to detect in individual model realizations unless we force the model with a scenario that has four times the observed emissions reduction.

Plain Language Summary The COVID-19 pandemic is slowing the rate of fossil fuel use, and thus impacting the carbon dioxide concentration in the atmosphere. Here we explore what this change in fossil fuel use does to carbon in the ocean. We use a climate model to estimate the change in ocean-atmosphere carbon exchange and ocean acidity. Since we don't yet know how much we will slow our fossil fuel use due to COVID, we make several informed guesses and see how our model ocean responds to each. We use the model to investigate whether the change that we model would be detectable in real world observations. We find that it is nearly impossible to detect a COVID-related change in ocean acidity with observations. It might be possible to detect a COVID-related change in ocean-atmosphere carbon exchange, but only if we use the most extreme guess, and only if we have enough observation stations in place to record it.

\section{Introduction}

The socioeconomic disruptions associated with the COVID-19 pandemic have caused an unprecedented drop in global emissions of carbon dioxide $\left(\mathrm{CO}_{2}\right)$ and other atmospheric pollutants. The year 2020 was characterized by a $6.4 \%$ decrease in global $\mathrm{CO}_{2}$ emissions relative to the previous year (Carbon Monitor Project, 2021; Liu et al., 2020), with average daily emissions declines peaking at $-26 \%$ in individual countries (Le Quéré et al., 2020). The duration and severity of the emissions decline in the future is as yet unknown, but anomalously low $\mathrm{CO}_{2}$ emissions are also expected in 2021 (Liu et al., 2020). The important role of $\mathrm{CO}_{2}$ emissions in the global carbon cycle and climate system motivates further research on this topic.

Several research groups are actively studying the impact of the COVID-related emissions reductions on the atmosphere and climate system. The latest World Meteorological Organization bulletin reports slight reductions in 2020 atmospheric $\mathrm{CO}_{2}$ levels $(-0.08$ to $-0.23 \mathrm{ppm})$ as a result of the COVID pandemic, though they emphasize that this reduction is difficult to detect given typical year-to-year variations in atmospheric $\mathrm{CO}_{2}$ ( \pm 1 ppm; World Meteorological Organization, 2020). A recent modeling study concurs that COVID-related reductions in atmospheric $\mathrm{CO}_{2}$ levels are likely undetectable, but also demonstrates that these short-term 
reductions will have a long-term (decadal or longer) influence on atmospheric $\mathrm{CO}_{2}$ concentrations due to the long-lived nature of $\mathrm{CO}_{2}$ in the atmosphere (Fyfe et al., 2021). Modeling studies suggest a modest or negligible impact of the emissions reductions on global atmospheric temperature (Forster et al., 2020; Fyfe et al., 2021). To date, no study has described the impact of COVID-related emissions reductions on the ocean. As the ocean carbon system is particularly susceptible to atmospheric $\mathrm{CO}_{2}$ levels, further study on this topic is warranted.

Previous modeling work implies that the COVID-related $\mathrm{CO}_{2}$ emissions reductions will have an immediate impact on ocean carbon uptake. Using an upper ocean box model that solves for the time rate of change of dissolved inorganic carbon in the surface mixed layer, McKinley et al. (2020) showed high sensitivity of air-sea $\mathrm{CO}_{2}$ flux to slight variations in the growth rate of the atmospheric partial pressure of $\mathrm{CO}_{2}\left(\mathrm{pCO}_{2}^{\text {atm }}\right)$ over the 1990s and 2000s. Using a global Earth system model, Laughner et al. (2021) find an anomalous $70 \mathrm{Tg} \mathrm{C} \mathrm{yr}^{-1}$ reduction in 2020 sea-to-air $\mathrm{CO}_{2}$ flux due to COVID. These findings prompt further investigation into the detection of COVID-related $\mathrm{CO}_{2}$ emissions reductions in ocean carbon observations.

Here, we explore the potential to detect COVID-related $\mathrm{CO}_{2}$ emissions reductions in two measurable quantities for ocean carbon: (1) $\Delta \mathrm{pCO}_{2}$, which is the difference between the partial pressure of $\mathrm{CO}_{2}$ in the surface ocean $\left(\mathrm{pCO}_{2}^{o c}\right)$ and the overlying $\mathrm{pCO}_{2}^{a t m}$ and determines the direction and, along with wind speed and solubility, the magnitude of the sea-to-air $\mathrm{CO}_{2}$ flux, and (2) surface ocean $\mathrm{pH}$, a measure of ocean acidity. Using ensembles of simulations conducted with a single Earth system model, we identify the fingerprint of COVID-related $\mathrm{CO}_{2}$ emissions reductions in these observable quantities. We then treat the individual model ensemble members as possible future $\Delta \mathrm{pCO}_{2}$ trajectories and use our findings to remark on the likelihood of fingerprint detection in future ocean carbon measurements.

\section{Methods}

\subsection{CanESM5 COVID Ensemble}

Our primary numerical tool is the Canadian Earth System Model version 5 (CanESM5), which consists of coupled atmosphere, ocean/sea ice, and land model components, and was designed to make estimates of historical climate change and variability, to provide future climate projections, and to initialize near-term predictions of the climate system (Swart et al., 2019). The terrestrial component of the model consists of the Canadian Land Surface Scheme (CLASS) and the Canadian Terrestrial Ecosystem Model (CTEM) that together simulate energy, water, and $\mathrm{CO}_{2}$ fluxes across the land-atmosphere boundary (Swart et al., 2019). The ocean component of the model is based on the Nucleus for European Modeling of the Ocean (NEMO), but has been configured for use in CanESM5 with a nominal $1^{\circ}$ horizontal resolution that refines to $1 / 3^{\circ}$ meridional grid spacing near the equator, 45 vertical layers with varying thickness from $6 \mathrm{~m}$ in the surface to $250 \mathrm{~m}$ at depth, and a collection of scientifically supported sub-grid scale mixing schemes (Swart et al., 2019). The ocean biogeochemical component of the model uses the Canadian Model for Ocean Carbon (CMOC) (Christian et al., 2010), a Nutrient, Phytoplankton, Zooplankton, Detritus (NPZD)-type biological model with updated carbonate chemistry routines following the Ocean Model Intercomparison Project biogeochemical (OMIP-BGC) protocol (Orr et al., 2017).

We analyze output from a large ensemble of CanESM5 simulations forced with four different $\mathrm{CO}_{2}$ emission scenarios (Figure 1a). This model simulation configuration is described in Fyfe et al. (2021), and hereafter referred to as the CanESM5 COVID ensemble. In each case, the atmospheric $\mathrm{CO}_{2}$ evolves prognostically, driven by $\mathrm{CO}_{2}$ emissions. Briefly, the first set of simulations (the control) consists of 30 ensemble members of CanESM5 integrated over 2015-2019 under SSP2-4.5 $\mathrm{CO}_{2}$ emissions and initialized with slightly perturbed climate states to capture internal climate variability. The remaining three ensembles follow the same initialization procedure with 30 ensemble members each over 2019-2040, but are forced with a COVID-like $\mathrm{CO}_{2}$ emissions reduction that begins in December 2019 and resolves by December 2021 (Figure 1a). Peak emissions reductions of 25\% (COVID-like), 50\% ( $2 \times$ COVID-like), and 100\% (4 $\times$ COVID-like) occur in May 2020 (Figure 1); these scenarios correspond to 2020 annualized emissions reductions of $16 \%, 32 \%$, and $63 \%$, respectively (Fyfe et al., 2021). We focus on the COVID-related $\mathrm{CO}_{2}$ 

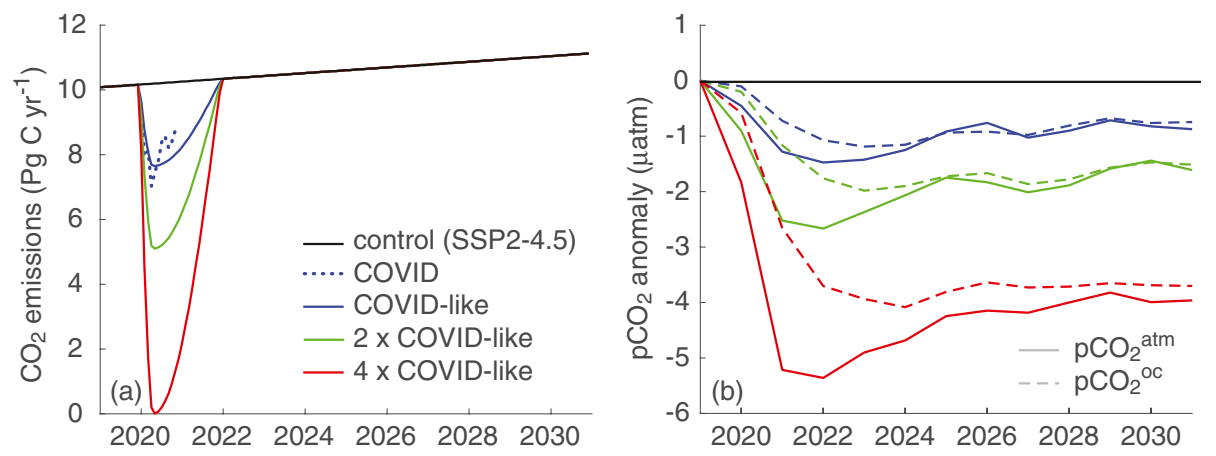

Figure 1. (a) Global-mean $\mathrm{CO}_{2}$ emissions $\left(\mathrm{Pg} \mathrm{C} \mathrm{yr}^{-1}\right.$ ) for the (black) control/SSP2-4.5, (blue) COVID-like, (green) $2 \times$ COVID-like, and (red) $4 \times$ COVID-like scenarios. Dotted blue line shows the emission history over 2020, as estimated by the Carbon Monitor project (Liu et al., 2020, last update November 30, 2020). (b) Global-, annual-, and ensemble-mean surface (solid) $\mathrm{pCO}_{2}^{a t m}$ and (dashed) $\mathrm{pCO}_{2}^{o c}$ anomaly ( $\mu$ atm; difference from control) simulated in the CanESM5 ensembles under the COVID-like emission scenarios. Adapted from Fyfe et al. (2021).

emissions reduction in this analysis; the interested reader is directed to Fyfe et al. (2021) and Gettelman et al. (2021) for an investigation of the impact of COVID-related aerosol emission reductions on the climate system.

CanESM5 is an appropriate tool for the exploration of the ocean carbon response to COVID-related emissions reductions. A previous evaluation of the CMIP6 historical simulation of CanESM5 via comparison with historical climatologies finds high spatial correlation $(r>0.9)$ of modeled and observed three-dimensional potential temperature, nitrate, oxygen, and dissolved inorganic carbon (Swart et al., 2019). However, the same study finds lower spatial correlations $(r=0.7)$ between modeled and observation-based historical air-sea $\mathrm{CO}_{2}$ flux (Swart et al., 2019), prompting our further evaluation of ocean observables $\Delta \mathrm{pCO}_{2}$ and surface ocean $\mathrm{pH}$ over the historical period. Figure S1a illustrates similar spatial patterns of annual-mean $\Delta \mathrm{pCO}_{2}$ across the global ocean between the CanESM5 control ensemble mean and version 2020 of the Landschützer et al. (2016) observation-based climatology (Landschützer et al., 2020) over 2015-2018, though we note regional differences in the magnitude and spatial extent of positive $\Delta \mathrm{pCO}_{2}$ across the equatorial Pacific, in the sign of $\Delta \mathrm{pCO}_{2}$ in the subtropical North Atlantic, and in the spatial extent of the positive $\Delta \mathrm{pCO}_{2}$ region in the eastern subtropical North Pacific. We also note a lack of observation-based estimates of $\Delta \mathrm{pCO}_{2}$ in the Arctic, where CanESM5 predicts large negative $\Delta \mathrm{pCO}_{2}$ values (Figure S1a,b). The CanESM5 control ensemble is capable of capturing the phasing and magnitude in the climatological seasonal cycle of $\Delta \mathrm{pCO}_{2}$ as measured at the Woods Hole Oceanographic Institution Hawaii Ocean Timeseries Site (WHOTS) buoy, though the spring minimum is deeper in approximately half of the CanESM ensemble members than observed (Figure S1b). While the annual mean surface ocean $\mathrm{pH}$ over 2015-2018 exhibits similar spatial patterns between modeled $\mathrm{pH}$ and an observation-based product (Gregor \& Gruber, 2020), the modeled $\mathrm{pH}$ is generally lower than that from observation-based estimates (Figure S2). As with $\Delta \mathrm{pCO}_{2}$, a lack of observation-based climatological estimates of $\mathrm{pH}$ in the seasonally ice covered Southern Ocean and Arctic precludes investigation of model-observation similarity in these regions. CanESM5 produces rates of historical ocean carbon uptake that are consistent with observational estimates of decadal mean $\mathrm{CO}_{2}$ fluxes and with independent estimates of cumulative anthropogenic carbon uptake at the global scale (Swart et al., 2019), suggesting that the simulated response of ocean carbon to atmospheric $\mathrm{CO}_{2}$ changes is reliable at the large scale.

\subsection{Statistical Approach}

We identify the COVID-related fingerprints in $\triangle \mathrm{pCO}_{2}$ and $\mathrm{pH}$ using CanESM5 COVID ensemble mean output that has been annually and globally averaged over 2019-2024. This 5 year period captures the time during which we observe the largest anomalies in atmospheric and oceanic $\mathrm{pCO}_{2}$ relative to the control ensemble across each of the COVID emissions scenarios (see also Figure 1b). We identify the fingerprint using ensemble and global-mean output to maximize the influence of external forcing and dampen the in- 
fluence of internal variability on the fingerprint (Lovenduski et al., 2016; McKinley et al., 2016; Schlunegger et al., 2019, 2020). The spatial pattern associated with the COVID-related fingerprint is estimated as the regression coefficient of the ensemble mean at each location onto the standardized fingerprint (subtract mean and divide by standard deviation) over 2019-2024 for each emission scenario. The statistical significance of these regression coefficients is assessed via a $t$ test that accounts for autocorrelation when estimating the effective sample size (Bretherton et al., 1999).

Detection and attribution of the COVID fingerprint is assessed by analyzing the set of 30 Pearson's correlation coefficients $(r)$ produced when correlating individual ensemble members with the corresponding fingerprint over 2019-2024. The statistical properties (mean, and standard deviation) of these coefficients are estimated via Fisher $z$-transformation, assuming a normal distribution. We use a $z$ test statistic at the 0.05 level to determine the significance of the difference in mean correlation relative to the control ensemble.

\section{Results}

The CanESM5 COVID ensemble predicts an anomalous decrease in surface $\mathrm{pCO}_{2}^{a t m}$ and $\mathrm{pCO}_{2}^{o c}$ due to the $\mathrm{CO}_{2}$ emissions reduction, as evidenced by the negative anomalies in annual mean, ensemble mean $\mathrm{pCO}_{2}^{\text {atm }}$ and $\mathrm{pCO}_{2}^{o c}$ calculated relative to the control/SSP2-4.5 emissions scenario (Figure 1b). Anomalously low $\mathrm{p}$ $\mathrm{CO}_{2}^{\text {atm }}$ peaks in 2021-2022, approximately 1-2 years after the largest emissions reduction, reflecting the mixing time of $\mathrm{CO}_{2}$ in the global atmosphere. At their peak, global mean anomalies in $\mathrm{pCO}_{2}^{\text {atm }}$ are $-1.5,-2.7$, and $-5.4 \mu \mathrm{atm}$ for the COVID-like, $2 \times$ COVID-like, and $4 \times$ COVID-like emission scenarios, respectively. Anomalously low $\mathrm{pCO}_{2}^{o c}$ peaks in 2023-2024, approximately 1-2 years after the largest $\mathrm{pCO}_{2}^{a t m}$ reduction, reflecting the equilibration timescale of the surface ocean mixed layer with atmospheric $\mathrm{CO}_{2}$ perturbations (McKinley et al., 2020). At their peak, global mean anomalies in $\mathrm{pCO}_{2}^{o c}$ are smaller in magnitude than the $\mathrm{pCO}_{2}^{\text {atm }}$ anomalies for the corresponding emission scenario $(-1.2,-1.9$, and $-4.1 \mu$ atm for the COVID-like, $2 \times$ COVID-like, and $4 \times$ COVID-like emission scenarios, respectively). Unlike the $\mathrm{CO}_{2}$ emissions anomalies (Figure 1a), the $\mathrm{pCO}_{2}^{a t m}$ and $\mathrm{pCO}_{2}^{o c}$ anomalies persist for the duration of the simulations (Figure 1b), due to the long-lived nature of $\mathrm{CO}_{2}$ in the atmosphere (Fyfe et al., 2021).

The difference between the evolution of $\mathrm{pCO}_{2}^{a t m}$ and $\mathrm{pCO}_{2}^{o c}$ following the COVID-like $\mathrm{CO}_{2}$ emissions reductions creates a unique fingerprint in $\Delta \mathrm{pCO}_{2}$ across the CanESM5 COVID ensemble (Figures 2a-2c). Figure 2 (top row) shows the evolution of the annual mean, global mean $\Delta \mathrm{pCO}_{2}$ from the 30 individual ensemble members (light gray) and the ensemble mean (black) across the three COVID scenarios. The fingerprint for each scenario is indicated as the colored part of the ensemble mean $\Delta \mathrm{pCO}_{2}$, capturing the temporal behavior over 2019-2024 (Figures 2a-2c). This fingerprint is characterized by an increase in $\Delta \mathrm{pCO}_{2}$ from 2019 to 2021, followed by a decrease over 2021-2024, and is most pronounced in the $4 \times$ COVID-like case and least pronounced in the COVID-like case. This inverted "V" fingerprint/time-series is unique; it arises due to the rapid slowdown and recovery of $\mathrm{CO}_{2}$ emissions and the $\sim 1$ year equilibration timescale for carbon between the atmosphere and the ocean mixed layer (Figure 1b; McKinley et al., 2020). In contrast, a typical year-on-year emissions reduction scenario - for example, a scenario that limits warming to $1.5^{\circ} \mathrm{C}$ - generates a slowly-changing $\Delta \mathrm{pCO}_{2}$ whose fingerprint would be challenging to distinguish (not shown).

The evolution of ocean acidification under COVID-like emissions reductions produces an almost imperceptible fingerprint in global mean surface ocean $\mathrm{pH}$. Here, the large and long-lived anthropogenic $\mathrm{CO}_{2}$ burden in the atmosphere drives continued ocean carbon uptake and thus decreasing global pH relative to the base period in all ensemble members over 2019-2040 (Figures 2d-2f). The rate of pH decrease briefly stagnates under COVID-like emissions reductions, with the biggest stagnation under the $4 \times$ COVID-like emissions scenario (Figure 2f). This fingerprint in surface ocean $\mathrm{pH}$ would be difficult to distinguish in the observational record due to large measurement uncertainty relative to the projected rate of $\mathrm{pH}$ decrease. Thus, for the remainder of our study, we focus our analysis efforts on the unique $\Delta \mathrm{pCO}_{2}$ fingerprint brought about by COVID-related emissions reductions. 

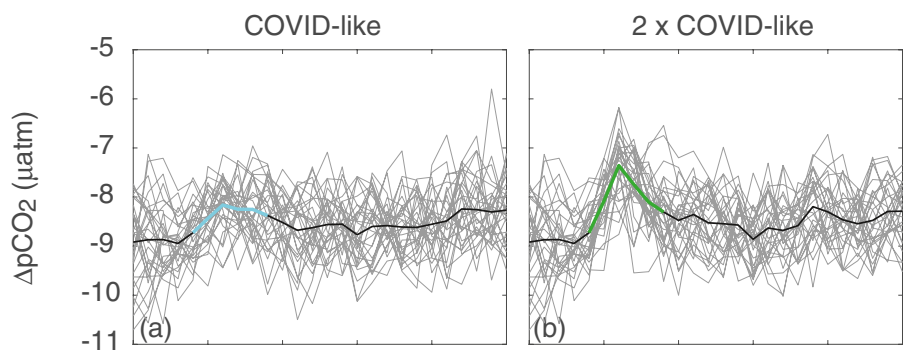

(b)

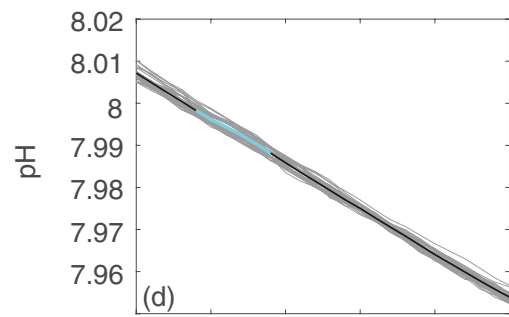

20152020202520302035

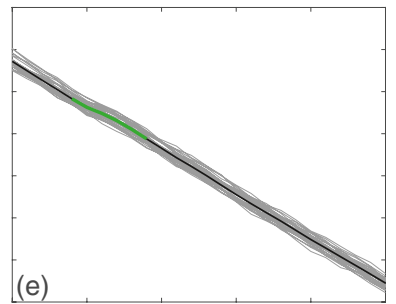

20152020202520302035

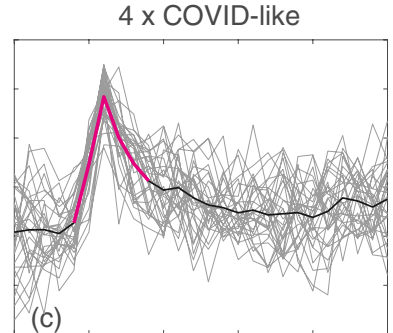

(c)

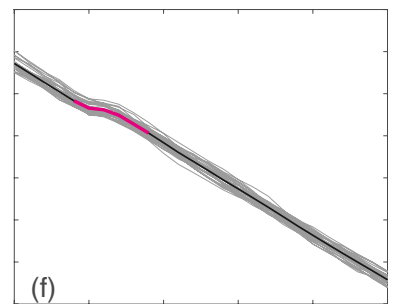

201520202025203020352040

Figure 2. COVID-related fingerprints in global-mean, annual-mean (top row) $\Delta \mathrm{pCO}_{2}\left(\mathrm{pCO}_{2}^{o c}-\mathrm{pCO}_{2}^{a t m} ; \mu \mathrm{atm}\right)$ and (bottom row) surface ocean $\mathrm{pH}$, simulated with the CanESM5 COVID ensemble. Gray lines show individual ensemble members, black line shows the ensemble mean, and colored lines show the COVID-related fingerprint over 2019-2024 under the (first column) COVID-like, (second column) $2 \times$ COVID-like, and (third column) $4 \times$ COVID-like emission scenarios.

The COVID-related fingerprints in $\Delta \mathrm{pCO}_{2}$ are characterized by a heterogeneous spatial pattern across the CanESM5 global ocean. Figure 3 shows the magnitude of the fingerprint signal at each location, masked for statistical significance. Under the COVID-like emission scenario, we find very few significant signals. The fingerprint signals become more widespread with larger emissions reductions, such that a majority of the global ocean experiences a fingerprint signal in the $4 \times$ COVID-like emissions scenario (Figure 3c).

Is it possible to detect our modeled $\Delta \mathrm{pCO}_{2}$ fingerprint in the real ocean, and to attribute the fingerprint to COVID-related emissions reductions? While the answer to this question is not yet attainable (the signal has not fully evolved in the real ocean as of this writing), we can treat the individual CanESM5 COVID ensemble members as equally likely $\Delta \mathrm{pCO}_{2}$ trajectories and examine their correlation to the ensemble mean. This model-based analysis will allow us to remark on the likelihood of future observational detection and attribution. Figure 4a shows the range of correlation coefficients across the 30 ensemble members under the four emission scenarios for the global mean $\Delta \mathrm{pCO}_{2}$. The mean correlation coefficient is near zero for the control simulation (not exactly zero due to the long term trend in $\Delta \mathrm{pCO}_{2}$ under SSP2-4.5), with a wide range; COV-

(a) COVID-like

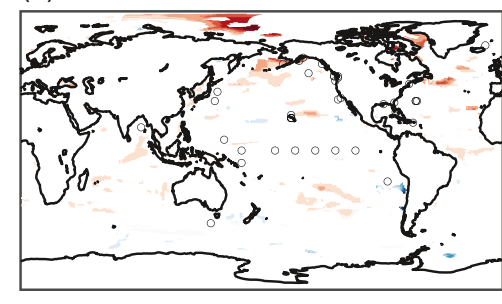

(b) 2 x COVID-like

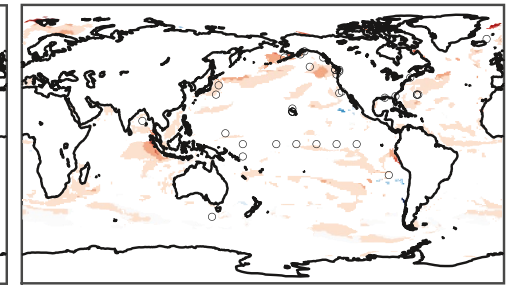

$\begin{array}{llllllllllll}-5 & -4 & -3 & -2 & -1 & 0 & 1 & 2 & 3 & 4 & 5\end{array}$ (c) 4 x COVID-like

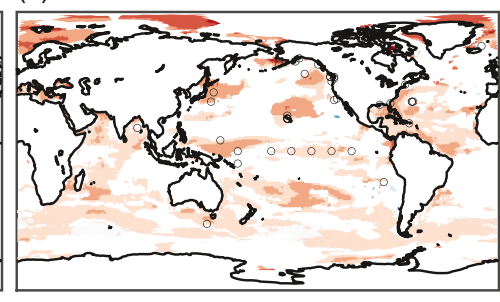

Figure 3. Spatial pattern of the COVID-related fingerprints in $\Delta \mathrm{pCO}_{2}\left(\mathrm{pCO}_{2}^{o c}-\mathrm{pCO}_{2}^{\text {atm }}\right.$; $\mu$ atm) under the (a) COVID-like, (b) $2 \times \mathrm{COVID}$-like, and (c) $4 \times$ COVID-like emission scenarios, calculated as the regression coefficient of $\Delta \mathrm{pCO}_{2}$ onto the standardized fingerprints. Statistically insignificant (at the $95 \%$ level) regression coefficients are shaded white. Black open circles indicate the locations of buoys capable of autonomous surface ocean $\mathrm{pCO}_{2}$ measurements from Sutton et al. (2019). 


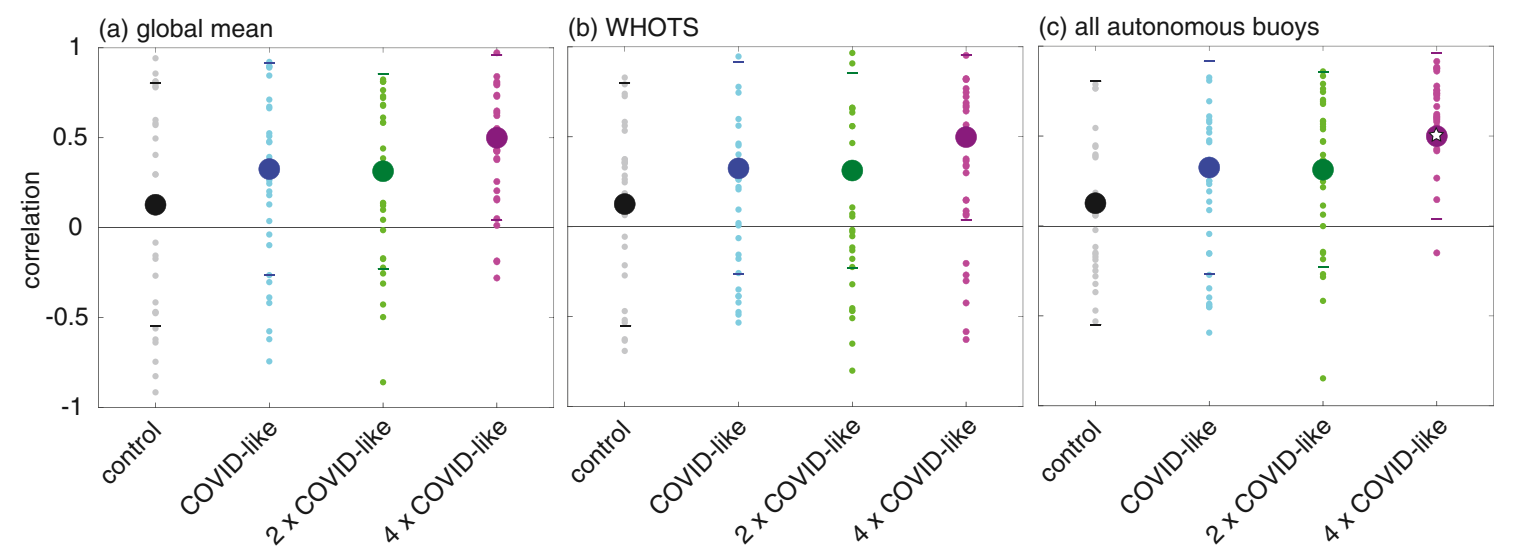

Figure 4. Detection and attribution of COVID-related fingerprints in $\Delta \mathrm{pCO}_{2}$ under four emission scenarios for (a) the modeled global-mean, (b) the WHOTS buoy location in the model, and (c) the mean of 40 autonomous buoy locations in the model, shown as the temporal correlation coefficients of individual ensemble members with the ensemble-mean fingerprint over 2019-2024. Small circles show the correlation coefficients from the 30 ensemble members, large circles show the mean correlation coefficients (starred if significantly different from the control), and dashes indicate $1 \sigma(67 \%)$ confidence intervals.

ID-like emissions reductions increase the mean and narrow the range, supporting the attribution of the $\triangle \mathrm{pCO}_{2}$ signal to COVID. There is enhanced likelihood of detection of the COVID signal from global-mean $\triangle \mathrm{pCO}_{2}$ observations with more severe reductions in emissions, as evidenced by the increasing mean correlation coefficient with larger emissions reductions. However, the range of correlation coefficients is only statistically different from zero (using the $\pm 1 \sigma$ or $67 \%$ confidence interval) in the $4 \times$ COVID-like scenario. Thus, while the evolution of the global mean $\Delta \mathrm{pCO}_{2}$ anomaly is potentially detectable in observations and attributable to COVID emissions, our model results suggest that an unrealistically large emissions reduction would be required for detection.

It is nearly impossible to detect and attribute the COVID-related fingerprint in $\Delta \mathrm{pCO}_{2}$ at a single observational site due to high local internal variability and measurement uncertainty. Figure 3 shows the location of buoys capable of near real-time autonomous surface ocean $\mathrm{pCO}_{2}$ measurements ( $<2 \mu$ atm uncertainty) as open black circles; these 40 observational buoys are discussed in detail in Sutton et al. (2019). Both a strong signal (COVID fingerprint) and low noise (internal variability) are required for detection at a single site. The CanESM5 COVID ensemble predicts the strongest $\Delta \mathrm{pCO}_{2}$ fingerprint signals in regions where few buoys are located, such as the Arctic. Under extreme emission reductions, a measurable ( $>2 \mu \mathrm{atm}$ ) fingerprint signal begins to emerge at several of the buoy sites (Figure 3c). However, even at a subtropical site with low internal variance, such as the WHOTS buoy, and under the most extreme forcing scenario, the mean fingerprint correlation is not significantly different from the control simulation (Figure 4b), challenging our ability to attribute the signal to COVID.

Detection and attribution of a COVID-related fingerprint in $\Delta \mathrm{pCO}_{2}$ from near real-time autonomous buoys is more likely when considering all 40 observational data streams simultaneously. Figure $4 \mathrm{c}$ reveals that, akin to the global-mean, the subsampled model $\Delta \mathrm{pCO}_{2}$ averaged across the 40 autonomous buoy locations has higher correlations with the fingerprint than that of a single buoy location. Further, stronger emissions reductions are potentially detectable from this suite of 40 data streams, as the correlation coefficients are significantly different from zero $(1 \sigma, 67 \%$ confidence interval). Similarly, under the $4 \times$ COVID emission scenario, the mean correlation coefficient is statistically different from the control ensemble (Figure 4c), suggesting a clear attribution of the signal to COVID.

\section{Conclusions and Discussion}

We use an ensemble of Earth system model simulations to identify and assess the detectability of a COVID-related fingerprint in $\triangle \mathrm{pCO}_{2}$ and surface ocean $\mathrm{pH}$. Our study reveals a unique fingerprint in modeled global mean $\triangle \mathrm{pCO}_{2}$ anomalies under COVID-like $\mathrm{CO}_{2}$ emissions reductions due to the rapid slowdown of emissions and the equilibration timescale for carbon in the upper ocean. We find no dis- 
cernible COVID fingerprint for modeled surface ocean $\mathrm{pH}$, but rather a slight slowing of the continuous $\mathrm{pH}$ decline due to ocean acidification. A detection and attribution analysis conducted on individual model ensemble members shows that the modeled $\Delta \mathrm{pCO}_{2}$ fingerprint is attributable to COVID emissions and potentially detectable in global-scale observations, but only if we force the model with unrealistically large emissions reductions. At local scales, however, observational detection is hampered by high internal variability.

Our results indicate that the detection of a COVID-related $\Delta \mathrm{pCO}_{2}$ fingerprint in future observations is more attainable from global-scale estimates, rather than regional or local measurements. While this is expected due to the low magnitude of internal variability at global scales and high variability at local scales (Diffenbaugh et al., 2020; Lovenduski et al., 2016), it nevertheless suggests that a large network of global-scale p $\mathrm{CO}_{2}^{o c}$ observations will be necessary to detect an abrupt emissions reduction signal. Recent efforts to collect and process disparate $\mathrm{pCO}_{2}^{o c}$ data streams into a single cohesive database (e.g., Sutton et al., 2019; Bakker et al., 2016) will be highly useful for detection efforts. Even so, the ocean carbon community will continue to rely on observation-based, gap-filled surface ocean $\mathrm{pCO}_{2}$ estimates to approximate the global-mean $\Delta \mathrm{pCO}_{2}$ and its temporal evolution. Continued improvement upon and testing of the reliability of these products is thus warranted (e.g., Gloege et al., 2021 in press).

The COVID-like emissions trajectory in combination with the slow response time of ocean carbon to emissions reductions produces a unique fingerprint in $\Delta \mathrm{pCO}_{2}$ that we exploited for detection and attribution in our study. A more difficult task that awaits our community is the detection of a continuous emissions reduction in ocean carbon that may come about to support climate change mitigation policy. This detection will be further challenged by to the relatively high uncertainty in the global carbon cycle (Peters et al., 2017). Yet, it will become necessary to demonstrate the efficacy of emissions reductions on ocean carbon in the near future.

\section{Data Availability Statement}

The data from the CanESM5 simulations used in this study will be published through the Government of Canada Open Data Portal, and can be accessed at http://crd-data-donnees-rdc.ec.gc.ca/CCCMA/publications/COVID19/. The $\mathrm{CO}_{2}$ emissions data for 2020 were provided by the Carbon Monitor Project (https:// www/.carbonmonitor.org.cn; last access: Janurary 20, 2021). This is PMEL contribution 5189.

\section{References}

This research was supported by the National Science Foundation (OCE1752724 and OCE-1948664). The authors' collaboration was facilitated in part by the Ocean Carbon and Biogeochemistry program through the Filling the Gaps in Observation-based Estimates of Air-sea Carbon Fluxes working group. The authors acknowledge the CCCma staff who contributed to producing these simulations. The WHOTS buoy air-sea $\mathrm{pCO}_{2}$ data are supported by the Office of Oceanic and Atmospheric Research of NOAA, U.S. Department of Commerce, including resources from the Global Ocean Monitoring and Observation program and are archived at https://doi.org/10.7289/ V5DB8043.
Bakker, D. C. E., Pfeil, B., Landa, C. S., Metzl, N., O'Brien, K. M., Olsen, A., et al. (2016). A multi-decade record of high-quality fCO2 data in version 3 of the Surface Ocean CO2 Atlas (SOCAT). Earth System Science Data, 8(2), 383-413. https://doi.org/10.5194/essd-8-383-2016 Bretherton, C. S., Widmann, M., Dymnikov, V. P., Wallace, J. M., \& Bladé, I. (1999). The effective number of spatial degrees of freedom of a time-varying field. Journal of Climate, 12(7), 1990-2009. https://doi.org/10.1175/1520-0442(1999)012<1990:tenosd >2.0.co;2

Carbon Monitor Project. (2021). GlobalCO2Emission-20201130.

Christian, J. R., Arora, V. K., Boer, G. J., Curry, C. L., Zahariev, K., Denman, K. L., et al. (2010). The global carbon cycle in the Canadian Earth System Model (CanESM1): Preindustrial control simulation. Journal of Geophysical Research, 115(G3), G03014. https://doi. $\operatorname{org} / 10.1029 / 2008 J G 000920$

Diffenbaugh, N. S., Field, C. B., Appel, E. A., Azevedo, I. L., Baldocchi, D. D., Burke, M., et al. (2020). The COVID-19 lockdowns: A window into the Earth system. Nature Reviews Earth and Environment, 1, 470-481. https://doi.org/10.1038/s43017-020-0079-1

Forster, P. M., Forster, H. I., Evans, M. J., Gidden, M. J., Jones, C. D., Keller, C. A., et al. (2020). Current and future global climate impacts resulting from COVID-19. Nature Climate Change, 10, 913-919. https://doi.org/10.1038/s41558-020-0883-0

Fyfe, J. C., Kharin, V. V., Swart, N., Flato, G. M., Sigmond, M., \& Gillett, N. P. (2021). Quantifying the influence of short-term emission reductions on climate. Science Advances, 7(10), eabf7133. https://doi.org/10.1126/sciadv.abf7133

Gettelman, A., Lamboll, R., Bardeen, C. G., Forster, P. M., \& Watson-Parris, D. (2021). Climate impacts of COVID-19 induced emission changes. Geophysical Research Letters, 48(3), e2020GL091. https://doi.org/10.1029/2020gl091805

Gloege, L., McKinley, G., Landschützer, P., Fay, A., Frölicher, T., Fyfe, J., et al. (2021). Quantifying errors in observationally-based estimates of ocean carbon sink variability. Global Biogeochemical Cycles, 5, e2020GB006788. (in press). https://doi.org/10.1029/2020GB006788

Gregor, L., \& Gruber, N. (2020). OceanSODA-ETHZ: A global gridded data set of the surface ocean carbonate system for seasonal to decadal studies of ocean acidification. Earth System Science Data, 13, 777-808. https://doi.org/10.5194/essd-2020-300

Landschützer, P., Gruber, N., \& Bakker, D. C. E. (2016). Decadal variations and trends of the global ocean carbon sink. Global Biogeochemical Cycles, 30(10), 1396-1417. https://doi.org/10.1002/2015GB005359,2015GB005359

Landschützer, P., Gruber, N., \& Bakker, D. C. E. (2020). An observation-based global monthly gridded sea surface $\mathrm{pCO}_{2}$ and air-sea $\mathrm{CO}_{2}$ flux product from 1982 onward and its monthly climatology. NCEI Accession 0160558. NOAA National Centers for Environmental Information. Dataset.Version 5.5 https://doi.org/10.7289/V5Z899N6 
Laughner, J. L., Neu, J. L., Schimel, D., Wennberg, P. O., Barsanti, K., Bowman, K., et al. (2021). The 2020 COVID-19 pandemic and atmospheric composition: Back to the future. Earth and Space Science Open Archive. https://doi.org/10.1002/essoar.10506081.1

Le Quéré, C., Jackson, R. B., Jones, M. W., Smith, A. J. P., Abernethy, S., Andrew, R. M., et al. (2020). Temporary reduction in daily global CO2 emissions during the COVID-19 forced confinement. Nature Climate Change, 10(7), 647-653. https://doi.org/10.1038/ s41558-020-0797-X

Liu, Z., Ciais, P., Deng, Z., Lei, R., Davis, S. J., Feng, S., et al. (2020). Near-real-time monitoring of global $\mathrm{CO}_{2}$ emissions reveals the effects of the COVID-19 pandemic. Nature Communications, 11(1), 5172. https://doi.org/10.1038/s41467-020-18922-7

Lovenduski, N. S., McKinley, G. A., Fay, A. R., Lindsay, K., \& Long, M. C. (2016). Partitioning uncertainty in ocean carbon uptake projections: Internal variability, emission scenario, and model structure. Global Biogeochemical Cycles, 30(9), 1276-1287. https://doi. org/10.1002/2016GB005426,2016GB005426

McKinley, G. A., Fay, A. R., Eddebbar, Y. A., Gloege, L., \& Lovenduski, N. S. (2020). External forcing explains recent decadal variability of the ocean carbon sink. AGU Advances, 1(2), e2019AV000. https://doi.org/10.1029/2019AV000149

McKinley, G. A., Pilcher, D. J., Fay, A. R., Lindsay, K., Long, M. C., \& Lovenduski, N. S. (2016). Timescales for detection of trends in the ocean carbon sink. Nature, 530(7591), 469-472. https://doi.org/10.1038/nature16958

Orr, J. C., Najjar, R. G., Aumont, O., Bopp, L., Bullister, J. L., Danabasoglu, G., et al. (2017). Biogeochemical protocols and diagnostics for the CMIP6 Ocean Model Intercomparison Project (OMIP). Geoscientific Model Development, 10(6), 2169-2199. https://doi.org/10.5194/ gmd-10-2169-2017

Peters, G. P., Le Quéré, C., Andrew, R. M., Canadell, J. G., Friedlingstein, P., Ilyina, T., et al. (2017). Towards real-time verification of CO2 emissions. Nature Climate Change, 7(12), 848-850. https://doi.org/10.1038/s41558-017-0013-9

Schlunegger, S., Rodgers, K. B., Sarmiento, J. L., Frölicher, T. L., Dunne, J. P., Ishii, M., \& Slater, R. (2019). Emergence of anthropogenic signals in the ocean carbon cycle. Nature Climate Change, 9(9), 719-725. https://doi.org/10.1038/s41558-019-0553-2

Schlunegger, S., Rodgers, K. B., Sarmiento, J. L., Ilyina, T., Dunne, J. P., Takano, Y., et al. (2020). Time of emergence and large ensemble intercomparison for ocean biogeochemical trends. Global Biogeochemical Cycles, 34(8), e2019GB006. https://doi.org/10.1029/2019gb006453

Sutton, A. J., Feely, R. A., Maenner-Jones, S., Musielwicz, S., Osborne, J., Dietrich, C., et al. (2019). Autonomous seawater $p \mathrm{CO}^{2}$ and pH time series from 40 surface buoys and the emergence of anthropogenic trends. Earth System Science Data, 11(1), 421-439. https://doi. org/10.5194/essd-11-421-2019

Swart, N. C., Cole, J. N. S., Kharin, V. V., Lazare, M., Scinocca, J. F., Gillett, N. P., et al. (2019). The Canadian Earth System Model version 5 (CanESM5.0.3). Geoscientific Model Development, 12(11), 4823-4873. https://doi.org/10.5194/gmd-12-4823-2019

World Meteorological Organization. (2020). Can we see the impact of COVID-19 confinement measures on CO2 levels in the atmosphere? WMO Greenhouse Gas Bulletin (number 16), 23 November 2020. 